\title{
Mulheres só fazem amor com homens? A Educação Sexual e os relacionamentos entre pessoas do mesmo sexo'
}

\begin{abstract}
Jimena Furlani *
Resumo: Neste artigo problematizo processos de produção das diferenças sexuais a partir de coleçõos de livros paradidáticos relativos à Educação Sexual. Tenho como referenciais os Estudos Culturais e os Estudos Feministas, articulados com a perspectiva pós-estruturalista de análise. Discuto significados conferidos à homossexualidade, procurando apontar caminhos para refletir: como, didaticamente, na Escola, é possível desconstruir e construir, positivamente, essa identidade sexual e de gênero? Respeitar a diversidade é promover a inclusão curricular? Questiono "representaçōes" sexuais e busco ensaiar modos de "desconstrução" de seus significados, especialmente aqueles acerca dos tipos de sujeitos que estabelecem relacionamentos sexuais e afetivos com pessoas do mesmo sexo. O procedimento desconstrutivo poderá sugerir formas de operar a prática pedagógica da Educação Sexual, em qualquer nível de ensino.
\end{abstract}

Palavras-chave: Educação Sexual; Estudos Culturais e Estudos Feministas; desconstrução; homossexualidades; formação de educadoras/res.

* Professora efetiva do Centro de Ciências Humanas e da Educação (FAED) - Universidade do Estado de Santa Catarina (UDESC); Pesquisadora em Educação Sexual e Formação de Educadoras(res); integrante do GEERGE (Grupo de Estudos de Educação, Sexualidade e Relações de Gênero - UFRGS), do NES (Grupo de Estudos da Sexualidade - UDESC), do LAGEF (Laboratório de Gênero e Família - UDESC) e do NEAB (Núcleo de Estudos Afro-Brasileiros UDESC), SC. Brasil. jimena@udesc.br

I. Artigo originário da Tese de Doutorado: "O Bicho vai pegar! Um olhar pós-estruturalista à Educação Sexual a partir de livros paradidáticos infantis", defendida em julho de 2005, na UFRGS - Universidade Federal do Rio Grande do Sul/Brasil, sob a orientação da Profa. Dra. Guacira Lopes Louro. Este artigo teve como orientações de composição e escrita as normas da ABNT e as recomendações da Revista Pro-Posições. Entretanto, assumo um "modo feminista de escrever", ou seja: I. oponho-me a qualquer linguagem sexista que tenha a forma masculina como regra geral. Explicito o masculino e o feminino, ora com linguagem inclusiva (ex.: meninos e meninas), ora, quando possível, utilizando termos neutros em gênero (por exemplo: criança). Não utilizarei "homem" para me referir à humanidade. 2. Escrevo na primeira pessoa. Assumo, portanto, uma postura contrária à suposta "neutralidade da ciência moderna", uma vez que os Estudos Feministas e suas/seus estudiosas/os são assumidamente interessadas/os numa sociedade menos desigual em gênero. 3. Nas citações bibliográficas, visibilizo a autoria citando o prenome e o sobrenome $\mathrm{da}(\mathrm{o})$ autora(or) quando da sua primeira aparição no texto. 


\title{
"Do women only make love with men?" - sexual education and relationships with people of the same sex
}

\begin{abstract}
This paper provides a discussion on sexual difference production processes with the study of two sexual education textbooks. My discussion is based on cultural and feminist studies, articulated with a post-structuralist perspective of analysis. Meanings granted to homosexuality are discussed, in order to show some ways to reflect on how it is didactically possible to deconstruct and construct this sexual and gender-based identity in a positive way at school. The paper questions if respecting diversity can promote curricular inclusion. Sexual representation and ways to "deconstruct» its meanings are discussed, especially those about the kinds of people who establish sexual and affective relationships with people of the same sex. The deconstructive procedure can suggest ways to operate the sexual education pedagogic practice, at any teaching level.
\end{abstract}

Key words: sexual education; feminist studies and cultural studies; deconstruction; homosexuality; development of educators.

Nos últimos anos tenho buscado problematizar a construção das diferenças e das identidades (de gênero, sexuais e étnico-raciais), no contexto da educação escolar, articulando tais reflexões com a formação de professoras e professores (Furlani, 2004, 2005a, 2005b, 2007b, 2007c). Em alguns casos, minhas análises têm partido de representações de livros didáticos (de Ciências) e paradidáticos (de Educação Sexual) destinados à Educação Infantil e aos Ensinos Fundamental e Médio. Entendo que o modo como o gênero e a sexualidade estão representados nesses artefatos pedagógicos e culturais produz significados que marcam e constituem não apenas o sujeito e as práticas normais, mas também os sujeitos e as práticas significadas na cultura como "desviantes", "não-autorizadas", "anormais" (por exemplo, para muitos, ainda, o relacionamento sexual e afetivo entre pessoas do mesmo sexo - a homossexualidade; ou, ainda, a "suposta inversão" de gênero - homens femininos e mulheres masculinas).

Processos discursivos constroem as diferenças nos sujeitos e essas, por sua vez, são representadas e significadas no social de muitas formas - os materiais didáticos são locais que explicitam representações e constituem esses sujeitos. É imprescindível, a qualquer processo de educação e de formação de educadoras/es (que busca, honestamente, explicitar as desigualdades sociais), duvidar da norma, questionar as hegemonias, pôr em questão a moralidade conservadora, explicitar os mecanismos históricos e políticos que marcam "os diferentes" como significativamente "indesejáveis". 
Disciplinas como a Educação Sexual ainda se constituem em tabus nos currículos escolares. No entanto, entendo que elas encontram, nos livros paradidáticos, seus maiores aliados. Quando buscamos pesquisas acadêmicas anteriores, o livro paradidático (como campo investigativo) ainda reúne menos análise que os livros didáticos. Entretanto, a cada ano, sua importância como recurso adicional no ensino tem apontado para a necessária investigação dos significados e dos efeitos de suas representações. Assim, as reflexōes que trago neste artigo irão procurar questionar os processos de produção das diferenças (especialmente as sexuais e de gênero) no âmbito de práticas educativas (a Educação Sexual) e de pedagogias culturais (o livro paradidático), apontando para possibilidades desconstrutivas de sua lógica de significação. Cabe, aqui, esclarecer que em momento algum procurei "analisar os livros" e/ou emitir qualquer "juízo de valor" acerca de seus conteúdos, de suas formas, de suas ilustrações, etc. Também não pretendi "adivinhar" ou "descobrir" as "reais intençōes" de suas autoras com essa ou com aquela ilustração, com esse ou com aquele texto. Para os Estudos Culturais, os livros, assim como qualquer artefato da cultura, constituem-se num meio... São e foram um pretexto para o meu "olhar" analítico... Constituem-se num local de representaçōes e de referência na construção das identidades culturais e das múltiplas posições de sujeito... São áreas onde as sexualidades e os gêneros estão e são materializados... Eles "refletem" o real da mesma forma que o constroem e da mesma forma que são construídos pelas representações sociais.

\section{Representação e desconstrução - recursos didáticos à Educação Sexual}

A perspectiva pós-estruturalista admite que são as muitas relações de poder, presentes nos processos de significação, que marcam e instituem as diferenças identitárias dos sujeitos sociais. Toda identidade cultural (e aqui me refiro a gênero, sexualidade, geração, etnia, raça, condição física, religião, nacionalidade, classe social, etc.) só apresenta sentido numa cadeia discursiva de diferenças: "o que ela é" será totalmente dependente "daquilo que ela não é", ou seja, o que é a homossexualidade é o oposto do que é a heterossexualidade (e assim, igualmente, em relação a ser homem ou mulher, masculino ou feminino, branco/a ou negro/a...). Quando a diferença cultural é estabelecida, geralmente, ela implica processos de exclusão, estratégias de divisão marcadas pela hierarquia, por diferentes escalas valorativas, por distintos sistemas de categorização que tornam positiva ou negativa a identidade em questão.

Para Tomas Tadeu da Silva (2001a, p.135) "sob a influência do pós-estruturalismo, uma análise do caráter do currículo (qualquer que seja ele), baseada nos Estudos Culturais, enfatizaria o papel da linguagem e do discurso nesse 
processo de construção [...]". Somadas a esse entendimento, as análises culturais trazem também o conceito de representação (a partir de Michel Foucault) como aquilo que discursivamente constrói a realidade. Quando olhamos para o currículo escolar e o vemos como representação, estamos considerando-o "como discurso, como signo, como prática de significação (Silva, 2001b, p.65)”.

As identidades culturais são constantemente produzidas e, poder-se-ia dizer, ensinadas por meio de suas representaçôes. Essas pedagogias da sexualida$\mathrm{de}^{2}$ e do gênero consideram a identidade, a diferença e o outro como uma questão política, que implica disputa social por representação. Nesse sentido, parece-me oportuno e provocativo fazer três perguntas: 1. Como os relacionamentos afetivos e sexuais, entre pessoas do mesmo sexo, são representados nos artefatos culturais/pedagógicos escolares? 2. Como essas representaçôes podem ser desconstruídas na Educação Sexual? 3. E, para aqueles e aquelas que, como eu, buscam uma educação de respeito às diferenças, de equidade de gênero, de reconhecimento da livre orientação sexual, de igualdade étnico-racial, como é possível ressignificar positivamente essas identidades e esses sujeitos a partir da Educação Sexual?

Uma possibilidade para responder essas questōes, talvez seja o proposital e assumido exercício analítico de desconstrução das representações. A desconstrução, termo criado pelo filósofo francês Jacques Derrida (1930- 2004) tem sido muito utilizada no campo das ciências sociais e humanas, nos últimos tempos, e de muitas maneiras. Para Derrida, desconstruir um texto é mostrar os modos como ele pode ser lido e explicitado em suas contradições e irredutibilidades, e uma possibilidade para isso é apontar as oposições binárias presentes nas tramas.

Todo texto comporta interpretações que, à primeira vista, parecem irreconciliáveis. Desconstruir um texto é desfazer as fronteiras entre as oposições, sobretudo a oposição sujeito/objeto, subvertendo a ordem e os valores hierárquicos tradicionais contidos nelas (Yamashiro, 2004).

No entanto, desconstruir um texto, um entendimento, uma representação, é também explicitar seu caráter construído (inventado, criado, forjado), ou

2. Guacira Louro (2000) cunhou a expressão "pedagogias da sexualidade" para referir-se ao complexo investimento exercido sobre a sexualidade e sobre os corpos de homens e mulheres por meio da produção de significados referentes aos modos pelos quais são constituídos. Instituições sociais como a escola, a mídia, a igreja, a lei, a medicina e outras tantas exercitam cotidianamente essas pedagogias: "Ali se aprende uma linguagem socialmente situada, que diz sobre o que falar e sobre o que silenciar, o que mostrar e o que esconder, quem pode falar e quem deve ser silenciado" (p.33). 
seja, é buscar perturbar, transgredir, desestabilizar e subverter a lógica de poder que estabelece aquela "verdade" como inquestionável, merecedora de status, de prestígio, de hegemonia...

\section{A relação sexual... Quando a afetividade faz a diferença}

O privilégio histórico do qual gozou o enfoque biológico-reprodutivo na Educação Sexual escolar pode ser apontado como um importante fator, não apenas de legitimação da heterossexualidade como o padrão hegemônico de relacionamento, mas da quase total ausência, nos livros escolares, de um enfoque afetivo e amoroso nos relacionamentos íntimos, de um modo geral. Embora culturalmente o amor romântico tenha recebido prestígio e incentivo desde os tempos que remontam ao século XII (Lins, 1997, p.80), a lógica pedagógica para justificar as relações sexuais entre as pessoas sempre encontrou, na indiscutível necessidade da reprodução, seu maior amparo e seu status de normalidade... Nessa lógica, a afetividade era dispensável.

Quais os efeitos de abordar a temática "relação sexual" por uma outra lógica que não a da compulsória reprodução? Que possíveis implicações uma ênfase afetiva confere ao entendimento da sexualidade? Que "novas" práticas sexuais acabam por se tornar "autorizadas", quando a afetividade entre as pessoas (independente do sexo) é posta como prioridade na justificativa para os envolvimentos íntimos, felizes e duradouros?

$\mathrm{Na}$ contemporaneidade, políticas de identidade sexual, sobretudo no período posterior ao advento do HIV/AIDS, nas décadas de 1980-1990, passaram a ressignificar a representação de práticas sexuais e a sua importância no contexto de uma sexualidade segura. Tal postura caminhou no sentido de dar novo significado ao entendimento da relação sexual, levando em consideração a variedade de práticas, possibilitando visibilizá-las no contexto escolar e sugerindo uma lógica plural para a Educação Sexual. Uma atitude, talvez, mais condizente com a contemporaneidade e com a demanda atual sobre a importância: do sexo seguro; da visibilidade de inúmeros sujeitos; do reconhecimento das identidades de gays, lésbicas, travestis, transexuais; do respeito àqueles que preferem o auto-erotismo (masturbação) ou àqueles que optam pela privação de parceiros (pelo sexo virtual, por exemplo) ou por outras formas de viver a sexualidade.

Quais os efeitos dessa abordagem plural? Em que medida essa abordagem estaria mais de acordo com a representação e o entendimento de uma sexualidade não atrelada ao enfoque reprodutivo ou exclusiva dele? Em que medida essa representação permite a explicitação de outras práticas sexuais e de outros sujeitos? 
A partir desses dois pontos por mim destacados $\left(1^{\circ}\right.$, uma sexualidade afetiva e não, necessariamente, reprodutiva; $2^{\circ}$, a pluralidade contemporânea nos relacionamentos e nas práticas sexuais), volto-me ao corpus analítico - os livros paradidáticos (Candia et al., 1996; Lopes, 2000). Nesses referenciais as representações apresentadas permitem a desconstrução da sexualidade hegemônica como sendo, apenas ela, a possibilidade aceitável, correta, legítima. A heterossexualidade - como única sexualidade legítima - pode ser subvertida, desestabilizada e fragilizada pelo entendimento da lógica gradual do desenvolvimento da confiança e do afeto entre pessoas que convivem (familiares e amigos) e que se gostam:

Desde que nascem, e ao longo de toda a sua vida, as pessoas gostam de estar juntas [...] (Lopes, 2000, L06, p.03) ${ }^{3}$.

Quando os meninos e meninas já são um pouco maiores, começam a se interessar por outras pessoas, além dos familiares [...] (Lopes, 2000, L06, p.05).

Além do carinho e da amizade, entre as pessoas também pode surgir a atração sexual (Lopes, 2000, L06, p.05, grifos das autoras).

O conceito de atração sexual, nessa representação, é o que vai possibilitar os contornos da aproximação corporal genital entre duas pessoas, levando ao ato sexual entre elas. "Ter relações sexuais" é o mesmo que "fazer amor", "[...] isso quer dizer que gostam de se encontrar a sós para se sentirem muito próximos" (Candia, 1996, L02, p.07). Nessa representação, o ato sexual aproxima-se tanto de um envolvimento carregado de afeto e carinho quanto da exclusividade do relacionamento entre adultos e, para isso, a linguagem textual foi sempre neutra e indefinida ("as pessoas"). Quando se escolhe essa forma lingüística, não há um direcionamento à heterossexualidade - e essa é uma escolha política dessa Educação Sexual. Portanto, destaco dois aspectos que me pareceram marcantes quanto à estratégia argumentativa do texto: primeiro, a linguagem sempre neutra em gênero, utilizando expressões tais como "as pessoas", "as crianças", "amigos e amigas"; segundo, a afirmação sobre as amizades com o seguinte teor:

[...] os meninos e as meninas [...] por vezes, têm uma amiga ou amigo preferido e é com ele que dividem jogos, conversam sobre o que pensam e sentem, estudam, praticam esportes ou trocam confidências [...] tentam também dividir os maus momentos, quando eles surgem. Além de carinho e amizade, entre as pessoas também pode surgir a atração sexual. (Candia, 1996, grifos meus).

3. (CSS, L06, p.03), leia-se: Coleção Sexo e Sexualidade, livro 06, página 03. 
O que torna o texto surpreendente, além do seu aspecto neutro em gênero, é que ele permite pensar que a atração erótica pode ocorrer entre pessoas do mesmo sexo. Neste sentido, penso que o material favorece a desconstrução da heterossexualidade como o modelo hegemônico, na medida em que permite que a/o professora/or que se utiliza do livro paradidático possa fazer a inclusão da homossexualidade, ou seja, possa apresentar aos alunos e às alunas o sentimento e a atração entre pessoas do mesmo sexo como igualmente legítimos e positivos e como uma possibilidade futura nos relacionamentos adultos.

Essa representação (Candia, 1996), que aborda o assunto "atração sexual" e, a seguir, "ato sexual - fazer amor", se, de um lado, não menciona abertamente os envolvimentos afetivos e sexuais entre pessoas do mesmo sexo, por outro, parece não se opor à discussão dessa forma de relacionamento, nem tampouco a inviabiliza. Muito pelo contrário! Para aquelas e aqueles professores/educadores atentos à inclusão curricular das identidades subordinadas (ou atentos à desconstrução da heterossexualidade como o "único" modelo possível), o livro paradidático apresenta uma estratégia textual que pode ser vista e utilizada como facilitadora da iniciativa docente de proporcionar esse tipo de discussão com crianças e jovens. E parece que essa postura vai ao encontro da discussão, quando menciona a existência de homens e mulheres homossexuais que preferem fazer amor com pessoas do mesmo sexo.

No meu entendimento, a Educação Sexual para crianças deve privilegiar a "afetividade mútua" como a justificativa para a aproximação das pessoas, no estabelecimento dos mais diversos relacionamentos (amizade, namoro, casamento, união). $\mathrm{O}$ afeto funciona como uma estratégia epistêmica, com efeitos diretos na representação da identidade homossexual, sobretudo de sua ressignificação social. Nesse sentido, é possível operar com uma possibilidade desconstrutiva, no âmbito dos saberes escolares, a partir da identificação e da problematização de dois pólos opostos, comumente presentes (embora "ocultos") nos currículos: reprodução versus afetividade. Afinal, o que "justifica" a união e o envolvimento sexual entre as pessoas? O projeto pessoal da reprodução? Ou a legitimidade dos sentimentos afetivos e da atração física entre elas?

O discurso textual das representações em Candia (1996) e Lopes (2000) materializa e privilegia a afetividade como o fator que ampara e possibilita, como normal e esperada, a relação sexual entre pessoas do mesmo sexo e entre pessoas do sexo oposto. Parece-me evidente que a estratégia argumentativa do texto coloca a relação sexual entre as pessoas como um ato justificado e autorizado, não pelo desejo futuro da reprodução, mas sim, pela afetividade e pelo prazer que, incontestavelmente, as une. Essa abordagem não é comum nos livros didáticos e/ou paradidáticos infantis. A esse respeito, Guacira Louro (1999) comentou que "[...] quando a dimensão do prazer está presente [...] ela 
tem como pressuposto exclusivo o desejo heterossexual, ou seja, é negada a possibilidade de que os sujeitos possam ter como objeto amoroso e de desejo alguém de seu próprio sexo" (p.135).

O texto de Candia (1996) faz diferenciação entre relação sexual e coito - e aqui é possível desconstruir outro binômio que aponto nessa Educação Sexual: relação sexual versus práticas sexuais. Para a autora, a relação sexual vai além do coito, da penetração vaginal. A troca de palavras carinhosas, de carícias e os beijos por todo corpo são apresentados como pertencentes ao momento íntimo que é prazeroso para ambos. A afinidade, o respeito, o carinho mútuos parece que devem ser mais valorizados do que a penetração, propriamente dita. Embora o livro mencione a existência de casais homossexuais, ele não ousa, por exemplo, enveredar para a descrição das possíveis práticas sexuais entre dois homens ou duas mulheres. Nem tampouco considera a masturbação como uma possibilidade entre os casais, sejam eles heterossexuais e/ou homossexuais.

Mencionar a atração erótica e a relação sexual entre pessoas do mesmo sexo já pode ser considerado um fator ousado, inovador e diferenciador dessa Educação Sexual e parece que Candia (1996) e Lopes (2000) param por aqui. Apresentar uma discussão sobre outras práticas sexuais (como o sexo oral, o sexo anal e a masturbação - individual ou mútua - inclusive no contexto da heterossexualidade), não tem sido comum na Educação Sexual infantil e tampouco esteve presente nos textos estudados.

No entanto, pergunto: a menção dessas práticas sexuais não seria mais adequada, dentro da lógica de assumir o sexo seguro como fundamental nas políticas de saúde e educação, de prevenção e de combate à proliferação de DSTs, HIV e AIDS? Em que medida o status conferido, nos livros didáticos e paradidáticos, à prática da penetração vaginal, não estaria reforçando a heterossexualidade e a sexualidade reprodutiva (apenas elas) como hegemônicas? Nos atuais tempos de HIV/AIDS/DSTs, a Educação Sexual não deveria tanto privilegiar a discussão das práticas sexuais quanto abordar tipos de relacionamentos afetivo-sexuais?

De certa forma, o privilegiamento da afetividade no ato sexual sugere os limites e as escolhas dessa Educação Sexual: parece que no nível do infantil prevalece a afetividade e a representação do "sexo por amor". Certamente, outras instâncias educacionais e culturais promoverão pedagogias da sexualidade que ensinarão o "sexo por prazer" e/ou por outros interesses "menos nobres" por dinheiro, por exemplo. Tudo no seu tempo... Esses aprendizados são "coisas de adulto" e, certamente, poderão ter espaço na Educação Sexual Adolescente, normalmente vista como inquestionável, de $5^{\mathrm{a}}$ a $8^{\mathrm{a}}$ séries (hoje, $6^{\circ}$ ao $9^{\circ}$ anos do Ensino Fundamental). Mas muitas/os educadoras/res consideram "tarde demais" a adolescência. Lopes (2000), neste sentido, explicitamente separa a 
relação sexual do aspecto afetivo (apenas), ou seja, considera que as pessoas podem se envolver, sexualmente, por desejo, por prazer, por interesses financeiros, etc. Ao perguntar: 'As pessoas só 'fazem amor' quando estão apaixonadas?", permite considerar outras realidades da vida sexual humana. O texto responde: 'Não, muitas pessoas 'fazem amor' por diversos motivos: porque estão com vontade, por dinheiro, porque acham a outra pessoa bonita, ou somente para sentirem prazer [...]" (Lopes, 2000, L06, p.13, grifos meus). Considerar e explicitar essas facetas da vida sexual humana é um aspecto inovador dessa Educação Sexual infantil e parece-me mais realista com os dias atuais.

É evidente a ênfase que os livros conferem ao valor da afetividade nos relacionamentos humanos - o que não me impede de perceber uma fragmentação entre sentimentos amorosos, de um lado, e práticas sexuais, de outro. Sem dúvida, essa abordagem que enfatiza o componente afetivo favorece a leitura da homossexualidade distante das intencionais, comuns e históricas associações com a irresponsabilidade, com a libertinagem, com a safadeza, com a promiscuidade - comuns nos discursos discriminatórios e intolerantes. Valorizar os sentimentos amorosos em detrimento dos sexuais - essa é uma representação que pode se constituir estratégica para a Educação Sexual, sobretudo na Educação Infantil e nos primeiros anos do Ensino Fundamental. Lopes (2000), no livro em que discute a relação sexual (Livro n.06), enaltece o romantismo e a afetividade como justificativas para o envolvimento sexual. O texto encerra a discussão, afirmando: "Mas quando você ama, a relação sexual dá mais prazer" (p.13). Portanto, a última abordagem no texto procurou reforçar a idéia de que quando duas pessoas se unem para fazer algo que, na sua "essência", é prazeroso, se houver entre elas um sentimento de afeto, tudo será melhor. Como estratégia pedagógica a essa Educação Sexual infantil, é feita uma analogia com aspectos da vida e do interesse da criança, valendo-se de uma ilustração num parque de diversões: um casal (um homem e uma mulher), juntos, sentados num carrinho dentro de um trem fantasma; ambos estão assustados, segurando as mãos.

Vou ensaiar um exercício desconstrutivo a partir dessa representação e buscar mostrar o caráter inventado das identidades. Afirmei em artigo recente, intitulado "Mitos e tabus sexuais - representação e desconstrução no contexto da Educação Sexual" (Furlani, 2007b), que o significado de um texto é sempre mutável. Significante e significado são escorregadios e escapam às tentativas de fixação. No contexto das identidades sexuais e de gênero um dos efeitos políticos da desconstrução talvez pudesse se constituir na possibilidade de descobrir partes do texto que estão dissimuladas e que interditam e regulam certas condutas e identidades.

Guacira Louro (1999), ao referir-se aos gêneros, afirmou: "desconstruir a polaridade rígida dos gêneros então, significaria problematizar tanto a oposi- 
ção entre eles quanto a unidade interna de cada um" (p.31-32). Para a autora, cada pólo contém o seu outro. Cada pólo é fragmentado e dividido. Cada pólo esconde a pluralidade. Há uma "lógica que define um lugar 'natural' e fixo para cada gênero".

A desconstrução trabalha contra essa lógica, faz perceber que a oposição é construída e não inerente e fixa. A desconstrução sugere que se busquem os processos e as condições que estabeleceram os termos da polaridade. Supõe que se historicize a polaridade e a hierarquia nela implícita (Louro, 1999, p.32).

Poderíamos pensar no processo de "desconstrução" como uma "metodologia" que opera buscando "abrir" o sentido do texto e, para isso, vou deslocar uma identidade cultural (a heterossexualidade) por outra (a homossexualidade). Vou iniciar com a representação do livro paradidático, conforme ilustração e texto a seguir:

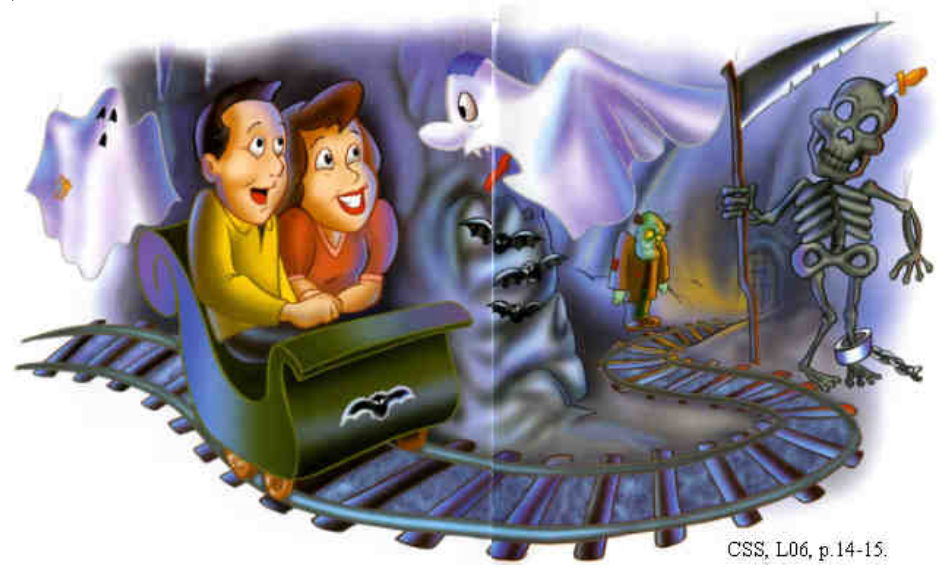

Figura 0 I - "A construção da heterossexualidade" Ilustração conforme Lopes (2000, Livro 06, p. I4- I5)

Se você for a um parque sozinho, você pode se divertir, pode até conhecer uma pessoa e brincarem juntos. Mas, se você for ao parque com uma pessoa de que você gosta muito, com certeza vai ser muito mais divertido. Você já sabe o que ele gosta, ele também sabe o que você gosta, vocês vão planejar juntos o que vão fazer, um faz companhia para o outro, lancham juntos, dividem as alegrias e medos (Lopes, 2000, L06, p.14-15, grifos meus). 
Comentei sobre Candia (1996) que a linguagem neutra em gênero possibilitou a utilização mais ampla do texto, considerando, também, os relacionamentos homossexuais e, eventualmente, uma possível inteligibilidade das crianças e jovens com esse modelo de relacionamento sexual-afetivo. Contudo, em Lopes (2000), a forma da linguagem usada é restrita ao masculino. Nesse caso, o que fica evidente é a demonstração da força que esta norma de tratamento ocupa - o status normatizador e hegemônico da retórica no masculino (um aspecto lingüístico sempre questionado pelos Estudos Feministas). Embora Lopes (2000) não tenha tido a preocupação em explicitar o relacionamento entre pessoas do mesmo sexo, entendo que este texto (como qualquer outro) pode permitir uma problematização. Pareceu-me possível promover um deslocamento da identidade visível para o seu "outro", ou seja, deslocar o texto da heterossexualidade para a homossexualidade. Querendo ser provocativa, vou me aproveitar da linguagem masculina do texto (que será rigorosamente mantida) e farei uma simples mudança de um personagem da ilustração. Utilizarei o texto escrito do livro, adequando-o à homossexualidade masculina, criando a imagem de dois homens sentados no carrinho do trem fantasma, conforme a ilustração a seguir:

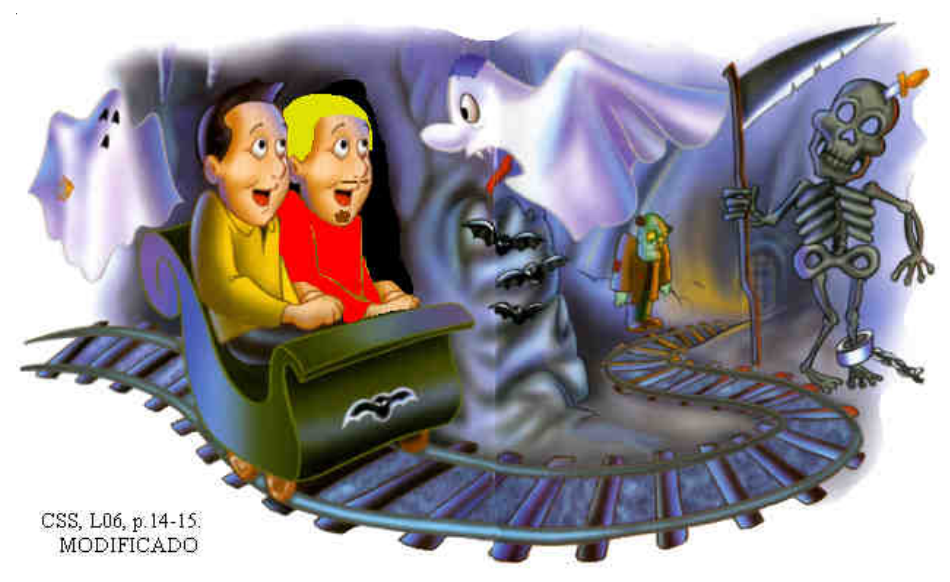

Figura 02 - "A construção da homossexualidade masculina"

llustração modificada, construída para o exercício desconstrutivo de deslocamento da identidade hegemônica, a partir de Lopes (2000, L06, p. I 4- I 5).

No contexto das tentativas escolares de inclusão de identidades subordinadas, pergunto: essa simples troca de personagens do desenho mostrado a crianças e jovens poderia ajudar a demonstrar o caráter construído e inventado dos 
padrões hegemônicos da sexualidade? Ao longo da história, nos processos de poder-saber que instauram os discursos legítimos e que garantem as representações positivas das identidades, a homossexualidade tem sido representada negativamente ou sobre ela tem prevalecido certo silêncio. Entretanto, a visibilidade conferida a esse tipo de relacionamento, nas últimas décadas, possibilita que o sentido do texto "montado" pareça plausível e talvez, até mesmo, para muitos/as, familiar.

Essa tentativa de desconstrução na Educação Sexual — que poderia acontecer em qualquer nível do ensino - ancora-se numa lógica de inteligibilidade que, nos dias atuais, os relacionamentos entre pessoas do mesmo sexo assumem. Embora ainda subordinada, a homossexualidade demonstrada na narrativa construída do trem fantasma, "faz sentido" para muitos/as (e certamente o faria para muitas crianças, para jovens e para professoras/res em cursos de Educação Continuada). Ou seja, o afeto mútuo e a convivência entre as pessoas são aspectos da vida que podem ser experimentados e deslocados (e considerados igualmente válidos) tanto para os relacionamentos heterossexuais como para os relacionamentos homossexuais. Em ambas as situações, mesmo alterando propositadamente a ilustração, a lógica desses sentimentos continuaria fazendo sentido entre pessoas do mesmo sexo - e justificando suas uniões (e não a reprodução). Essa atitude, por parte das/os professoras/res, em qualquer nível do ensino, entendo ser um ato deliberado e político de inclusão de identidades subordinadas - que poderiam ser mulheres, pessoas negras, indígenas, portadores de necessidades especiais, etc. —, numa lógica de significação positiva desses sujeitos. Um ato que vai ao encontro do respeito às diferenças na acolhida da multiplicidade humana.

A demanda pela discussão das sexualidades não normativas (sobretudo a homossexualidade) parece inevitável e cada vez mais evidente, sobretudo se considerarmos que as identidades subordinadas têm sido visibilizadas no meio cultural. As mudanças sociais do final do século XX têm sugerido e criado condiçôes para que as escolas se deparem com situaçôes em que a discussão das sexualidades seja problematizada, quer pela determinação curricular (este aspecto mais incomum, no Brasil), quer pelo questionamento discente, ou ainda pelas iniciativas de professores/as em atividades didáticas, como a que acabo de ensaiar. "E esse é um dos principais motivos por que as pessoas se unem. Para construir uma história a dois, com sonhos, planos, confiança e respeito." (Lopes, 2000, L06, p16).

Lógicas argumentativas, como a explicitada na citação anterior, na medida em que "justificam" os relacionamentos entre as pessoas (pela afetividade, pelo "sonho" comum, pela busca de felicidade - e não pela reprodução), favorecem, sugerem, encorajam e legitimam a inclusão curricular de outras formas de viver os afetos, os prazeres, os desejos. 


\section{Mas... "Mulheres só fazem amor com homens?" 4}

Essa é a pergunta que o próprio livro paradidático faz (Candia, 1996, L02, p.08-09), após a discussão sobre relação sexual entre um homem e uma mulher. A representação mostra uma ilustração: um casal deitado na grama de um parque; ao lado, um caminho onde circulam várias pessoas: um menino e uma menina; duas mulheres lado a lado; dois homens lado a lado; um homem só. A ilustração é acompanhada do seguinte texto escrito:

Habitualmente imaginamos um homem e uma mulher tendo relaçôes sexuais. Mas, às vezes, não é assim. Alguns homens preferem estar com outros homens e, nesse caso, dá-se o nome de homossexuais. Já as mulheres que gostam de estar com mulheres são denominadas lésbicas. O que é mesmo importante é que cada pessoa escolha quem mais gosta e respeite as preferências dos outros (Candia, 1996, L02, p.10, grifos meus).

E frase interrogativa ("Mulheres só fazem amor com homens?"), além de estimular o/a leitor/a a considerar outras possibilidades da sexualidade para os relacionamentos afetivos e sexuais, desestabilizando o status único da heterossexualidade, inquestionavelmente posicionou a mulher como o sujeito central da ação - o sujeito que decide e escolhe sobre sua sexualidade. Esta frase foi substituída, recentemente, quando a coleção foi editada com outro título e com outra editora, passando a ter a referência José Morfa et al. (2002). Todo o texto mantém-se igual, exceto a frase introdutória: em vez de "Mulheres só fazem amor com homens?", a atual edição pergunta: "Homens só fazem amor com mulheres?”. É indiscutível que a linguagem escrita institui a diferença de gênero... O processo de mudança da frase, de uma edição para outra, explicita disputas por representação e transforma o "homem" no sujeito ativo da sexualidade. Isso não é algo sem efeitos na educação de gênero.

Para Louro (1999, p.64), as diferenças que hierarquizam os sujeitos estão, constantemente, sendo produzidas no meio social, através de processos lingüísticos e discursivos, num campo que é político, uma vez que nele estão implicadas relações de poder.

Sem dúvida, na Escola, no currículo, nas disciplinas, nas normas regimentais, nas formas de avaliação, nos materiais didáticos, a linguagem reflete e reproduz os significados que marcam as desigualdades de gênero, sexuais, raciais, etc. Desigualdades essas que podem contribuir para a manutenção das representações que constroem o preconceito, a discriminação, o sexismo, etc.

4. Pergunta retirada de Candia ( 1996, L02, p. I0). 
É possível avançar para as formas através das quais as diferenças são produzidas e nomeadas. A indagação de como (e por que) determinadas características (físicas, psicológicas, sociais, etc.) são tomadas como definidoras de diferenças. A diferença é sempre atribuída no interior de uma dada cultura. São precisamente os discursos, os códigos, as representaçôes que atribuem o significado de diferente aos corpos e às identidades. A "diferença sexual" leva a "diferenças materiais" que são "simultaneamente marcadas e formadas por práticas discursivas” (Butler, 1999, p.153, grifos da autora).

O efeito discursivo sobre as identidades pode ser visto quando, no livro 02 , Candia (1996), na seção Glossário, define os termos "homossexual" e "lésbica":

HOMOSSEXUAL: homem que quase sempre prefere fazer amor com outro homem (p. 24, grifos meus).

LÉSBICA: mulher que quase sempre prefere fazer amor com outra mulher (p.24, grifos meus).

Quais os efeitos de utilizar o termo homossexual apenas para os homens? Usar a expressão quase sempre prefere para referir-se ao relacionamento estabelecido entre as pessoas homossexuais... Qual o significado de quase sempre prefere? Quais os seus efeitos? Em que medida o texto sugere tratar-se de relacionamentos incertos, indefinidos, imprecisos, eventuais, de dúvida pessoal? Atrelar a relação homossexual e lésbica ao interesse sexual eventual pode levar a uma representação adjetivada pela fragilidade, pela incerteza e pela provisoriedade desses relacionamentos? (ver Furlani, 2007a, p.172). Em que medida esse discurso tem sido usado como estratégia cultural para justificar a homofobia por parte de segmentos conservadores e moralistas da sociedade?

Penso que uma forma de mostrar a fragilidade do argumento acima, bem como de desconstruir a heterossexualidade, seja mostrar seu igual caráter construído, ao contrapô-lo a uma definição, igualmente "inventada", sob a mesma lógica:

HOMEM HETEROSSEXUAL: homem que quase sempre prefere fazer amor com mulher (texto construído para desconstrução da heterossexualidade, neste artigo).

MULHER HETEROSSEXUAL: mulher que quase sempre prefere fazer amor com homem (texto construído para desconstrução da heterossexualidade, neste artigo).

Essa proposital "montagem" de significados, inteligível a ambas as identidades sexuais (à heterossexualidade e à homossexualidade) é, propositadamente, irônica, histórica e política - pois explicita os jogos de poder, contingentes e 
circunstanciais, existentes no meio social nos processos de representação - no estabelecimento dos saberes que "dizem sobre" as identidades e seus sujeitos. Nesse sentido, o próprio texto (Candia, 1996) ajuda a mostrar a inconsistência do argumento do seu glossário:

Desde que nascemos, e ao longo de toda a vida, precisamos e gostamos de estar com outras pessoas. Podemos ter sentimentos diferentes em relação aos outros: amizade, carinho, paixão e atração sexual... Eles podem surgir entre um homem e uma mulher, entre dois homens ou entre duas mulheres (Candia, 1996, L.02, p.23, grifos meus).

Ou seja, o texto também concede aos casais homossexuais os mesmos sentimentos conferidos à heterossexualidade. A partir deste exemplo, penso que é possível, também, (e por que não?) voltar ao texto do "trem fantasma" e exercitar o deslocamento a partir da homossexualidade feminina.

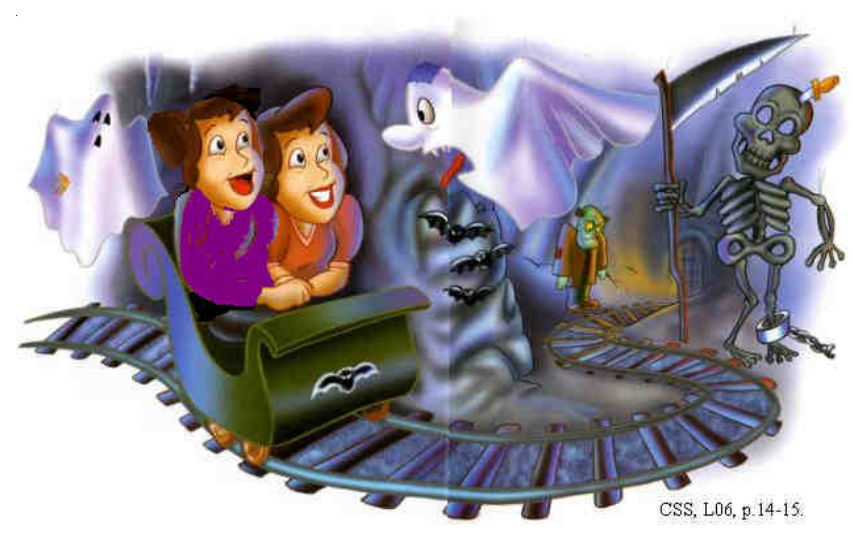

Se você for a um parque sozinha, você pode se divertir, pode até conhecer uma pessoa e brincarem juntos. Mas, se você for ao parque com uma pessoa de que você gosta muito, com certeza vai ser muito mais divertido. Você já sabe o que ela gosta, ela também sabe o que você gosta, vocês vão planejar juntas o que vão fazer, uma faz companhia para o outra, lancham juntas, dividem as alegrias e medos (texto modificado em gênero, grifos meus).

Figura 04 - "A construção da homossexualidade feminina" - Ilustração modificada, construída para o exercício desconstrutivo a partir de Lopes (2000, L06, p. I 4- I 5).

Além de adequar, propositadamente, a ilustração ao relacionamento afetivosexual entre duas mulheres, ouso alterar também o texto escrito, conferindolhe a coerência em gênero, no feminino, sobretudo porque seu início, marcado pela neutralidade, parte do argumento que tem como sujeito "a pessoa" - termo feminino que permite construir a representação voltada a explicitar a homossexualidade feminina. 
Outra possibilidade para a Educação Sexual é apresentar o entendimento da multiplicidade humana a partir dos diferentes arranjos familiares. Candia (1996) apresenta quatro representações de família: em página dupla, uma ilustração mostra um prédio residencial, onde quatro janelas abertas, dispostas horizontalmente, lado a lado, mostram distintos arranjos familiares ${ }^{5}$. Interessa-me, em especial, a representação de família da segunda janela, que mostra duas mulheres com um bebê. $\mathrm{O}$ texto que precede as quatro ilustrações não menciona, diretamente, a família formada por pessoas do mesmo sexo, embora a imagem das mulheres com a criança possa sugerir um casal de lésbicas. Aponto para o potencial de inclusão curricular da identidade homossexual feminina que o livro paradidático permite fazer, a partir do texto apresentado que, se por um lado, não explicita a homossexualidade, não impede, por outro, que a/o professora/or o faça.

Claudia Fonseca (2002, p.269) afirma que as famílias contemporâneas têm sido marcadas por uma multiplicidade de conformaçóes, entre elas, aquelas famílias constituídas por pessoas do mesmo sexo, favorecidas, principalmente pelo contexto emergente de visibilidade nacional e mundial da homossexualidade, nos últimos anos. Para a autora, "[...] parceiros do mesmo sexo ganharam um espaço importante; se a afeição é a verdadeira base do relacionamento, por que o casal seria limitado a um relacionamento heterossexual centrado em torno da reprodução biológica?” (Fonseca, 2002, p.272).

Parece que, mais uma vez, o argumento da "afetividade mútua" constitui-se numa produtiva abordagem didático-metodológica à Educação Sexual de crianças e jovens, para aqueles/as que buscam apresentar os relacionamentos entre pessoas do mesmo sexo como possíveis, legítimos, positivos e esperados para sexualidade humana.

\section{Os efeitos da representação... Da desconstrução... Da exclusão.}

Embora nos referenciais estudados (Lopes, 2000; Candia, 1996) haja menção da homossexualidade como uma possibilidade de relacionamento legítimo à sexualidade humana, essa não é a regra nas publicaçôes infantis presentes na

5. Na primeira janela - um homem adulto sentado à mesa, segura um copo; ao seu lado uma criança estica o braço tentando alcançar um bolinho, trazido numa bandeja por uma mulher adulta que, de pé, parece servi-los. Na terceira janela - um homem, adulto, de pé em cima de um banquinho, com avental, espana o pó de uma estante. Ao fundo, a porta se abre e aparece uma mulher adulta, segurando uma pasta executiva. À sua frente uma criança com os braços abertos corre ao seu encontro. $O$ homem observa a cena, olhando para criança da sua posição de trabalho. Na quarta janela - uma senhora idosa, de cabelos brancos, faz tricô olhando para TV à sua frente; uma menina, entre a senhora idosa e a TV, aponta para o aparelho, como se estivesse chamando atenção para algo. Ao fundo, no plano frontal, um homem adulto, sentado numa poltrona, lê um jornal. 
Escola. A ausência dessa representação pode fazer-nos pensar nos possíveis efeitos dessa prática ou, mais precisamente, nos possíveis sentidos atribuídos a uma dada identidade, quando, no currículo geral, ela não é referida, nomeada ou visibilizada.

Sobre essa "deliberada" ignorância, Guacira Louro (1999) manifesta-se quando discute a importância de não apenas "escutar" o que é dito sobre os sujeitos, mas também de perceber o não-dito, o que é silenciado sobre eles:

[...] nada é mais exemplar disso do que o ocultamento ou a negação dos/as homossexuais - e da homossexualidade - pela escola. Ao não se falar a respeito deles e delas, talvez se pretenda "eliminá-los/as", ou, pelo menos, se pretenda evitar que os alunos e as alunas "normais" os/as conheçam e possam desejá-los/ as. Aqui o silenciamento - a ausência da fala - aparece como uma espécie de garantia da "norma" (p.67-68).

A ignorância deve ser analisada "como um efeito do conhecimento, de fato, como seu limite, e não como um estado originário ou inocente" (Britzman, 1995, p.154). Talvez a ausência de informações acerca de certos aspectos da sexualidade não deva ser vista, simplesmente, como um não-conhecimento. Entendo que a ignorância pode se traduzir numa deliberada oposição ao saber. Esse "desejo de não saber" talvez aponte, por parte de quem o afirma, para uma arrogante explicitação de "já saber o necessário sobre" ou uma incapacidade, uma pretensa má vontade e relutância para admitir e reconhecer a existência do "outro", daquele que é diferente, do marginal. Nesse sentido, a ignorância pode ser compreendida "[...] não como carência de consciência, mas como uma resistência ao poder do conhecimento" (Luhmann, 1998, p.150) ${ }^{6}$.

Também é interessante considerar "o desejo pela ignorância como performativo" (Louro, 2004, p.69). Ou seja, quando o indivíduo manifesta a recusa pelo saber (por exemplo, falar, discutir ou saber sobre a homossexualidade), ele está também, supostamente, recusando (e eximindo-se de) qualquer envolvimento com essa identidade. Como se, ao afirmar: "Eu não conheço... Eu sou completamente ignorante em relação ao assunto gay e lésbico...", estivesse também afirmando: "Eu não tenho nada a ver com isso" - ou seja, parece reforçar sua isenção - garantida pela ignorância em relação a essa identidade.

Butler (2000) afirmará que a identidade, qualquer que seja, não é algo essencial que defina o indivíduo, mas sim um efeito da repetida performance de

6. Essa discussão, que coloca em xeque a deliberada ignorância das identidades subordinadas, tem sido desenvolvida por teóricas/os queer, entre elas Luhmann (1998), Britzman (1995), Louro (1999, 2004a). No capítulo 06 deminha tese (Furlani, 2005a), quando discuto uma "Abordagem Queer à Educação Sexual", retorno a essa questão. 
certos signos e convenções culturais, por exemplo, as várias significações do gênero e da sexualidade construídas nos contextos culturais e sociais.

Ainda que seja uma referência ausente ou esporádica no contexto do currículo escolar, a homossexualidade torna-se imprescindível como identidade cultural, na medida em que remete e acentua a sua representação oposta (a heterossexualidade), sobretudo no que diz respeito aos modelos hegemônicos de família, aos relacionamentos amorosos, às práticas sexuais, aos sujeitos, aos estilos de vida. Ao colocarem o sexo no discurso (Foucault, 1993), as pessoas e as instituições sociais constroem não apenas as identidades hegemônicas, mas também as subordinadas.

Assim, podemos compreender por que as identidades "alternativas", mesmo quando excluídas ou negadas, permanecem ativas (e necessárias): elas se constituem numa referência para a identidade heterossexual; diante delas e em comparação a elas a identidade hegemônica se declara e se sustenta (Louro, 2000, p.31).

Foucault afirmou que a história da sexualidade é, na verdade, a história dos discursos produzidos acerca da sexualidade, que constroem os sujeitos, seus corpos, suas identidades, suas práticas. Ora, parece que nos deparamos com um impasse, se nos colocamos diante do insistente "silêncio" da Escola em relação aos aspectos subordinados da vida sexual humana. Jeffrey Weeks (2000) lembra que Foucault, ao fazer a crítica à "hipótese repressiva", mostrou como a sexualidade "não pode ser caracterizada como um 'regime de silêncio', mas, ao contrário, como um constante e historicamente cambiante incitamento ao discurso sobre o sexo" (p.51). Talvez seja por isso que a Escola não pode mais "deixar" a mídia, por exemplo, "falar sozinha" sobre a sexualidade. Contribuir para uma sociedade de respeito às diversidades, que busque a equidade de gênero, a livre orientação sexual e a igualdade étnico-racial é colocar-se, política e assumidamente, em favor da Educação Sexual, em todos os níveis de ensino.

\section{Algo mais para ajudar a pensar...}

Parece-me que a explicitação das identidades subordinadas, comumente ausentes dos currículos escolares, pode constituir-se num primeiro passo para uma Educação Sexual voltada a minimizar as desigualdades sociais. As representações problematizadas parecem apontar para condições históricas atuais, que favorecem a visibilidade, sobretudo de relacionamentos afetivos e sexuais entre pessoas do mesmo sexo, na medida em que explicitam tais identidades. Nas coleçôes (Lopes, 2000; Candia et al., 1996), os textos são garantidos por uma lógica de inteligibilidade à identidade homoerótica nas suas representações. 
Nas últimas três décadas do século XX, os movimentos gay, lésbico e queer, além de provocar uma pluralização da política de identidade no que se refere às suas reivindicações (que passaram a dar mais ênfase no acesso aos direitos civis) possibilitaram, também, a visibilidade de múltiplas facetas do gênero e da sexualidade. Essa pluralidade abalou, fundamentalmente, a epistemologia sexual - as formas de se conhecer a sexualidade. Novas condiçôes culturais permitiram que, no espaço escolar, tivesse ocorrido, mesmo que timidamente, a emergência de certas alterações e inclusões curriculares no tocante às identidades sexuais e de gênero. Entre essas condições podemos destacar: a visibilidade e a repercussão política do movimento gay e lésbico no Brasil e no mundo; o espaço que a temática vem ocupando nas mídias; o advento do HIV/AIDS e a "obrigatoriedade" de sua discussão em todo o contexto social; o surgimento e a expansão de grupos acadêmicos no País com pesquisas e publicações na área; a ainda tímida inclusão temática em cursos de formação de professoras/res; as políticas públicas de discussão da Educação Sexual a partir dos Parâmetros Curriculares Nacionais (PCN) (Furlani, 2007b).

O relacionamento entre pessoas do mesmo sexo (assim como seus sujeitos) pode ser apresentado na Educação Sexual, pelo menos por meio de duas abordagens: para crianças (na Educação Infantil e no Ensino Fundamental) a partir da diversidade hoje existente nos muitos modelos de família e a partir da afetividade mútua e espontânea que leva as pessoas a estabelecerem relacionamentos afetivos. O caráter sexual pode ser mais enfatizado na Educação Sexual adolescente, sobretudo pela necessidade de ênfase no cuidado e na responsabilidade com as práticas sexuais e com a adoção do sexo seguro.

Independentemente do nível de ensino, a discussão da sexualidade não deve se privar de mostrar o quanto a vida humana é normatizada, significada e hierarquizada. A busca por uma sociedade de paz, de respeito e de convivência pacífica passa pelo reconhecimento da diversidade, qualquer que seja ela, como positiva. Questionar as muitas formas de preconceito e de exclusão social é papel de uma Escola que quer e que constrói uma sociedade menos sexista, menos racista, menos misógina e menos homofóbica - e isso começa na Educação Infantil.

\section{Referências bibliográficas}

BRITZMANN, Deborah. Is there a queer pedagogy? Or, stop reading straight. Educational Theory, v.45, n. 02, p.151-165, 1995.

BUTLER, Judith. Corpos que pesam: sobre os limites discursivos do sexo. In: LOURO, Guacira Lopes (Org.). O corpo educado: pedagogias da sexualidade. Belo Horizonte: Autêntica, p. 151-172, 2000. 
CANDIA, Caterina Marassi; BOTELLA, Marcedes Palop; LOPEZOSA, Pilar Millagón; MORFA, José R. Díaz. Minha primeira coleção de iniciação sexual e afetiva. São Paulo: Impala Brasil Editores, 1996.

FONSECA, Cláudia. A vingança de Capitu: DNA, escolha e destino na família brasileira contemporânea. In: BRUSCHINI, Cristina; UNBEHAUM, Sandra G. (org.). Gênero, democracia e sociedade brasileira. FCC, Editora 34, 2002.

FOUCAULT, Michel. História da sexualidade. A vontade de saber. 11. ed. Rio de Janeiro: Graal, 1993. v.1.

FURLANI, Jimena; LISBOA, Thaís, Maes. Subsídios à Educação Sexual a partir de estudo na internet. In: MEYER, Dagmar; SOARES, Rosangela. Corpo, gênero e sexualidade. Porto Alegre: Mediação, pp.41-61, 2004.

FURLANI, Jimena. O bicho vai pegar! Um olhar pós-estruturalista à Educação Sexual a partir de livros paradidáticos de educação infantil. 2005. Tese (Doutorado em Educação). Universidade Federal do Rio Grande do Sul, Programa de Pós-Graduação em Educação. Porto Alegre: PPG Edu/UFRGS. 2005a.

FURLANI, Jimena. Gêneros e sexualidades: políticas identitárias na Educação Sexual. In: GROSSI, Miriam Pillar; BECKER, Simone; LOSSO, Juliana C. M.; PORTO, Rozeli M.; MULLER, Rita de C. F. (Orgs.). Movimentos sociais, Educação e sexualidade. Rio de Janeiro: Editora Garamond, 2005b. (p.219-238. Coleção Sexualidade, Gênero e Sociedade).

FURLANI, Jimena. Mitos e tabus da sexualidade humana - Subsídios ao trabalho em Educação Sexual. 3. ed. Belo Horizonte: Autêntica, 2007a.

FURLANI, Jimena. Mitos e tabus sexuais - representação e desconstrução no contexto da Educação Sexual. In: RIBEIRO, Paulo Rennes Marçal et al. (Org). Sexualidade, cultura e Educação Sexual-propostas para reflexão. Araraquara: Unesp, 2007b. (Série Temas em Ed. Escolar, 07).

FURLANI, Jimena. Educação Sexual: do estereótipo à representação - argumentando a favor da multiplicidade sexual, de gênero e étnico-racial. In: RIBEIRO, Paula Regina Costa (Org.). Corpo, gênero e sexualidade - Discutindo práticas educativas. Rio Grande: Editora da FURG, 2007c. p.46-58.

LOPES, Cida. Coleção Sexo e Sexualidade. [S.L.] BrasiLeitura, [2000].

LOURO, Guacira Lopes. Gênero, sexualidade e Educação - Uma perspectiva pós-estruturalista. 3 ed. Petrópolis: Vozes, 1999.

LOURO, Guacira Lopes. Pedagogias da sexualidade. In: LOURO, Guacira (org.). O corpo educado - Pedagogias da sexualidade. Belo Horizonte: Autêntica, p.07-34, 2000.

LOURO, Guacira Lopes. O corpo estranho - ensaios sobre sexualidade e teoria queer. Belo Horizonte: Editora Autêntica, 2004.

LUHMANN, Suzanne. Queering/Queryng Pedagogy? Or, Pedagogy is a pretty queer thing. In: PINAR, Willian (org.). Queer theory in Education. New Jersey \& London: Lawrence Eribaum Associates Publishers, p. 141-155, 1998. 
MORFA, José R. Dias; CANDIA, Caterina Marassi; LOPEZOSA, Pilar Migallón; BOTELLA, Mercedes Palop. O nosso livro de sexualidade. São Paulo: Editora Caramelo, 2002.

SILVA, Tomaz Tadeu da. Teoria cultural e Educação - um vocabulário crítico. Belo Horizonte: Autêntica, 2000.

SILVA, Tomaz Tadeu da. Documentos de identidade - uma introdução às teorias do currículo. Belo Horizonte: Autêntica, 2001a.

SILVA, Tomaz Tadeu da. O currículo como fetiche - a poética e a política do texto curricular. Belo Horizonte: Autêntica, 2001b.

SOARES, Rosângela. Fica comigo gay - o que um programa de TV ensina sobre uma sexualidade juvenil? In: LOURO, G. L.; NECKEL, J. F.; GOELLNER, S. V. (orgs.). Corpo, gênero e sexualidade. Um debate contemporâneo na educação. Petrópolis, RJ: Vozes, p.136-148, 2003.

WEEKS, Jeffrey. O corpo e a sexualidade. In: LOURO, Guacira Lopes (org.). O corpo educado - pedagogias da sexualidade. Belo Horizonte: Autêntica, p.37-82. 2000.

YAMASHIRO, Setu-Co. 2004. Desconstrução. A crítica que se pretende literatura. Revista Ângulo. Disponível em http://angulo.fatea.br/angulo88_artigo04.htm. Acesso em 29 outubro 2004.

Recebido em maio de 2007 e aprovado em agosto de 2007. 